\title{
Distal radyoulnar eklem ve ulnokarpal kompleks anatomisi
}

\author{
Distal radioulnar joint and ulnocarpal complex anatomy
}

Murat İpteç, Bilge Özkan, Mehmet Eren

Başakşehir Çam ve Sakura Şehir Hastanesi, El Cerrahisi Kliniği, İstanbul

Ön kol eklemi; distal radyoulnar eklem (DRUE), proksimal radyoulnar eklem ve interosseöz membran (IOM) ile temelde üç kısımdan oluşan bir eklemdir. DRUE; bir kemiğin (ulna başı) silindir şeklindeki bir bölümünün başka bir kemik üzerinde bu silindir bölüme karşılık gelen bir konkaviteye (sigmoid çentik) oturması ile oluşan trokoid tipi bir eklemdir. DRUE, ön kol pronosupinasyonu sırasında el bilek optimal fonksiyonu için hayati önem taşır. Stabilizasyonu hem kemik hem de yumuşak dokular tarafından sağlanmaktadır. Ancak stabilite büyük ölçüde yumuşak doku stabilizatörlerine bağlıdır. Sonuçta ortaya çıkan hareket rotasyon veya dönme hareketleridir. Pronasyon ve supinasyon olarak da bilinen bu dönme hareketi, ön kolun radius başının merkezinden ulnar başın foveasına uzanan uzunlamasına bir eksen etrafinda oluşan harekettir. DRUE'de üç düzlemde hareket meydana gelir: 1) Ön kol ekseninde uzunlamasına rotasyon, 2) dorsal-palmar translasyon ve 3) proksimal-distal translasyon. DRUE'yi değerlendirmek için yaygın olarak kullanılan 3 önemli anatomik gösterge vardır. 1) Ulnar varyans distal ulna ile radius arasındaki uzunluk ilişkisini tanımlar. 2) Ön düzlemde, DRUE, ön kolun anatomik uzun eksenine $20^{\circ}$ eğik ancak radyoulnar dönme eksenine paralel olarak oturur. Bu ilişki, pronosupinasyon arkı boyunca DRUE üzerinde eşit kuvvet aktarımına izin verir. 3) Sagittal düzlemde, radius son pronasyon aralığında ulnanın daha iyi yerleşmesine izin veren, arkaya doğru bir bükülme sergiler. Triangular fibrokartilaj kompleks (TFKK), ulnar karpustan ulnaya iletilen sıkıştırıcı yükleri absorbe eden; kontrol ve yük aktarımının önemli mekanik özelliklerine sahip karmaşık bir üç boyutlu yapı olarak tanımlanabilir. TFKK bir bütün olarak DRUE'nin birincil stabilizatörü olarak kabul edilir. İnterosseöz membran (IOM), radius ve ulnayı neredeyse tüm uzunlukları boyunca birbirine bağlayan geniş bir bağ yapısıdır. IOM'nin ana işlevi, radius ve ulna arasındaki ilişkiyi pronosupinasyon arkı boyunca stabilize etmektir.

Anahtar sözcükler: distal radyoulnar eklem (DRUE); sigmoid çentik; pronosupinasyon; triangular fibrokartilaj kompleks (TFKK)
Forearm joint; it is basically a three-part joint with the distal radioulnar joint (DRUJ), the proximal radioulnar joint and the interosseous membrane (IOM). DRUJ; it is a trochoid type joint formed by the fit of a cylindrical part of a bone (ulnar head) to a concavity (sigmoid notch) corresponding to this cylindrical part on another bone. DRUJ is vital for the optimal function of the wrist during forearm pronosupination. Its stabilization is provided by both bone and soft tissues. However, stability is highly dependent on soft tissue stabilizers. The resulting movement is rotation or rotational movements. This rotational movement, also known as pronation and supination, is the movement that occurs around a longitudinal axis that extends from the center of the radial head of the forearm to the fovea of the ulnar head. In DRUJ, movement occurs in 3 planes: 1) Longitudinal rotation in the forearm axis, 2) dorsal-palmar translation and 3) proximal-distal translation. There are 3 important anatomical indicators commonly used to evaluate DRUJ. 1) Ulnar variance describes the length relationship between distal ulna and radius. 2) In the frontal plane, the DRUJ sits inclined $20^{\circ}$ to the anatomical long axis of the forearm but parallel to the radioulnar rotation axis. This relationship allows an equal transfer of force on the DRUJ throughout the pronosupination arc. 3 ) In the sagittal plane, the radius exhibits a posterior bend that allows better insertion of the ulna in the last pronation interval. Triangular fibrocartilage complex (TFCC), which absorbs compressive loads transmitted from the ulnar carpus to the ulna; It can be defined as a complex 3D structure with important mechanical properties of control and load transfer. TFCC is considered as the primary stabilizer of DRUJ as a whole. The interosseous membrane (IOM) is a large connective structure that connects the radius and ulna along almost their entire length. The main function of IOM is to stabilize the relationship between radius and ulna along the pronosupination arc.

Key words: distal radioulnar joint (DRUJ); sigmoid notch; pronosupination; triangular fibrocartilage complex (TFCC)

- Illetişim adresi: Uzm. Dr. Murat İpteç, Başakşehir Çam ve Sakura Şehir Hastanesi, El Cerrahisi Kliniği, İstanbul

Tel: 0536 - 3347737 e-posta: muratiptec@hotmail.com

- Geliș tarihi: 15 Mayıs $2021 \quad$ Kabul tarihi: 27 Mayıs 2021

ORCID iD: Murat İpteç, 0000-0002-2049-5966 • Bilge Özkan, 0000-0001-8513-2165 • Mehmet Eren, 0000-0002-3303-0092 
n kol eklemi; distal radyoulnar eklem (DRUE), proksimal radyoulnar eklem ve interosseöz membran (IOM) ile temelde üç kısımdan oluşan bir eklemdir. Distal radyoulnar eklem, ön kol ekleminin distalinde bulunan; ön kol ve karpus rotasyonu sırasında stabil bir nokta oluşturan eklemdir. ${ }^{[1]}$

Semptomatik distal radyoulnar eklem problemlerinin büyük bir çoğunluğu; eklem yüzeylerinin uzunluğunu, şeklini ve yönelimini sağlayan yapıların bozulmasından kaynaklanmaktadır. Bu yapılar DRUE, ulnokarpal eklem kıkırdağı, ulnokarpal eklem bağları, ekstansör karpi ulnaris ve pronator kuadratus kası olarak sıralanabilir. DRUE ön kol pronosupinasyonu sırasında el bilek optimal fonksiyonu için hayati önem taşır. ${ }^{[1]}$

Ulna başı ile sigmoid çentik arasında yer alan kemik yüzey ilişkisi inklinasyon, ulnar yükseklik ve sigmoid şekle göre değişkenlik gösterir. Sigmoid çentiğin dört adet alt tipi mevcuttur ve en fazla görüleni düz yüzlü tiptir (Şekil 1). Bundan dolayı osteokartilaginöz bir volar dudak, çentik konkavitesini derinleştirerek stabiliteyi artırır. ${ }^{[2]}$

Varyasyonlar DRUE'nin inklinasyonunda da mevcuttur. DRUE inklinasyonu; sigmoid çentik ile ulna DRUE eklem yüzü arasından çizilen çizgi ile ulna uzun aksına karşıı gelen çizgi arasında yer alan açı ile belirlenir (Şekil 2). Tolat ve ark., bunu koronal planda olan gözlemleri sonrası tespit etmişlerdir. ${ }^{[2]}$

Tip I; Paralel tip: Radyoulnar ekleme karşılık gelen yüzler radius ve ulna uzun aksına paraleldir.

Tip II; Oblik tip: Radyoulnar ekleme karşılık gelen yüzler, distali ulnara doğru eğimli olacak şekilde obliktir.

Tip III; Ters oblik tip: Radyoulnar ekleme karşılık gelen yüzler, distali radyale doğru eğimli olacak şekilde obliktir (Şekil 3). ${ }^{[3]}$

Distal radyoulnar eklem Tolat tipleri tip I \%55, tip II $\% 33$, tip III \%12 sıklıkla görülür. Tip I DRUE, sigmoid çentik ulna uzun aksına paraleldir ve açı $0^{\circ}$ ile $10^{\circ}$ 'dir. Tip II DRUE, sigmoid çentiğin yüzeyi proksimale bakar ve açı $10^{\circ}$ 'den fazladır. Tip III DRUE, yüzey distale bakar ve açı $10^{\circ}$ 'den azdır. ${ }^{[2,3]}$

Sigmoid çentiğin yarıçapı ulna başından yaklaşık $\% 50$ daha büyüktür ve bu durum pronasyon ve supinasyon sırasında rotasyona ve kaymaya izin verir. Supinasyonun en yüksek derecesinde eklem yüzü teması palmar dudakta 2-3 mm kadar olur. ${ }^{[4]}$

Ön kol nötralde iken radius ile ulna başının kıkırdak yüzünün yaklaşık \%60'ı temas halindedir. Ancak ileri supinasyon ve pronasyonda yalnızca \%10 kadar kıkırdak yüzey temas halindedir (Şekil 4). Ileri rotasyonlarda DRUE stabilitesi, daha çok etrafını saran bağ ve

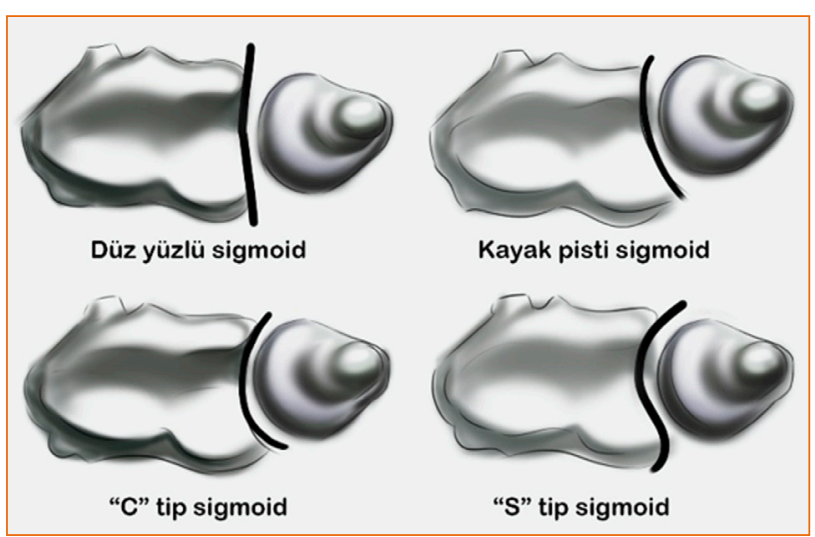

Şekil 1. Sigmoid çentik alt tipleri.

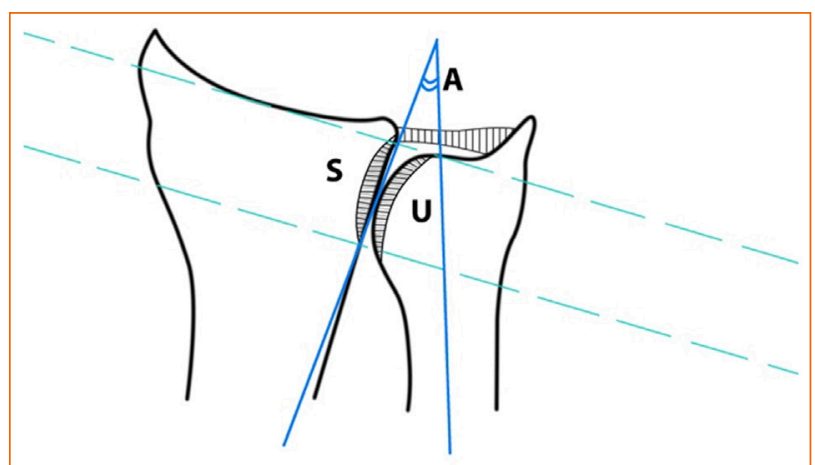

Şekil 2. Koronal planda distal radyoulnar eklem (DRUE) inklinasyon ölçümü. Sigmoid artiküler yüzey $(S)$, ulna artiküler yüzey (U), DRUE açısı (A).

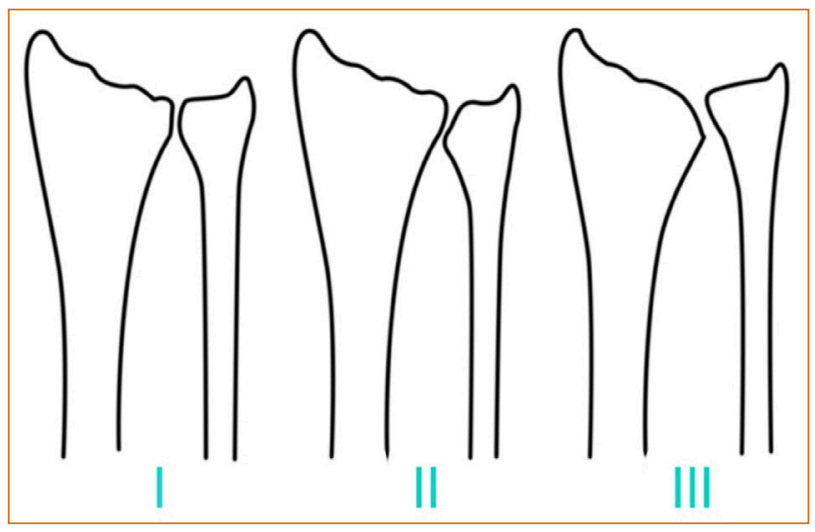

Şekil 3. Distal radyoulnar eklem (DRUE) Tolat tipleri: Paralel (I), oblik (II), ters oblik (III).

kasların yardımı ile sağlanır. Bu da DRUE kapalı çıkıklarının çoğunun neden el bileği aşıı supinasyonu veya aşıı pronasyonunda iken olduğunu açıklar. ${ }^{[4]}$

Sigmoid çentik kemik yapısı DRUE stabilitesinin \%20'sini sağlar. Ileri derecede olan ön kol rotasyonlarında bu oran daha da azalır. DRUE stabilizasyonu hem kemik hem de yumuşak dokular tarafindan 


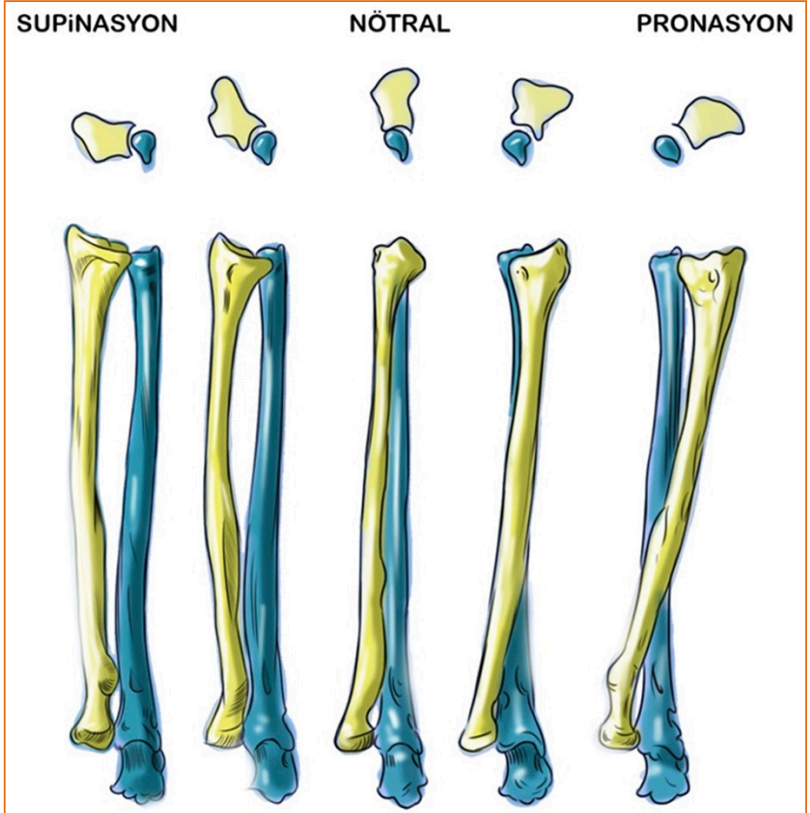

Şekil 4. Nötral, supinasyon ve pronasyon sırasında distal radyoulnar eklem (DRUE) kıkırdak teması.

sağlanmaktadır. Asıl DRUE stabilitesi yumuşak doku yapıları tarafından sağlanır. Statik yapılar olan dorsal ile palmar radyoulnar bağlar birincil stabilizatörlerdir. Dorsal ve volar radyoulnar bağlar DRUE stabilizasyonunu sağlamada en önemli yumuşak doku yapılarıdır. Radyoulnar bağın derin lifleri zengin kanlanması olan foveada, yüzeyel lifleri ise ulnar stiloid tabanı etrafına yapışır. Bu bağlar, ileri derecede pronosupinasyon hareketleri sırasında instabiliteyi önlemek için gerilir. ${ }^{[5,6]}$ Distal ulnanın uç kısmı triangular fibrokartilaj kompleks (TFKK) ile bitişik olarak hiyalin kıkırdak ile kaplanmıştır. TFKK'nin eklem diski yoluyla medial karpustan ulna üzerinden ön kola aktarılan yükün absorpsiyonundan sorumlu olduğu düşünülmektedir.

Distal radyoulnar eklem kapsülü, ulnotrikuetral bağ ve ulnolunat bağ, interosseöz membran ve triangular fibrokartilaj kompleks DRUE'nin statik stabilizasyonuna katkı sağlar. Dinamik stabilizatörler ise pronator kuadratus kası, ekstansör karpi ulnaris (EKU) tendonu ve ön kol orta hattında yer alan interosseöz bağdır. ${ }^{[7]}$

Distal radyoulnar eklemdeki ana yük taşıma ekseni, radyokarpal birim, sabit ulna etrafinda pronosupinasyonda sigmoid çentik boyunca eğik biçimdedir. Hareket çizgisi, pronasyonda distal dorsalden, supinasyonda proksimal palmara doğrudur. ${ }^{[7]}$

Ulna başı iki eklem yüzünden oluşur; sigmoid çentikte radyoulnar eklem diğeri ise ulnokarpal eklemdir.

\section{DISTAL RADYOULNAR EKLEM (DRUE) KEMIK ANATOMISI}

Distal radyoulnar eklem; bir kemiğin (ulna başı) silindir şeklindeki bir bölümünün başka bir kemik üzerinde bu silindir bölüme karşılık gelen bir konkaviteye (sigmoid çentik) oturması ile oluşan trokoid tipi bir eklemdir. ${ }^{[8]}$ Sonuçta ortaya çıkan hareket rotasyon veya dönme hareketleridir. El bileğinde yaklaşık \%80 oranında, sigmoid çentiğin volar tarafında, ulnanın palmar translasyonuna destek oluşturan eklem dişı osteokartilajinöz bir dudak bulunur. ${ }^{[9]}$ Distal radiusun volar ulnar köşesi, her ikisinin de kilit taşıdır. Hiyalin kıkırdak ile kaplı olan ulnar kutup, TFKK ile distalde eklem yapan ulnar başın yuvarlak kısmıdır. ${ }^{[7]}$ Fovea, ulnar stiloidi ulnar kutuptan ayıran iyi vaskülarize küçük bir alandır. ${ }^{[10,11]}$ Kıkırdaktan yoksundur ve dorsal radyoulnar ligamentin (DRUL) ve palmar radyoulnar ligamentin (PRUL) derin dallarının yapışma yeridir. Ön kolun dönme ekseninin distal ucu fovea'dan geçer. Ulnar stiloid çıkıntı, DRUL ve PRUL'nin yüzeysel dallarının yapışma yeri olarak görev yaparak ulnanın distal ucunun dorsoulnar yönünde uzanır. Ulnar stiloid çıkıntı hemen dorsalinde, EKU tendonu için bir oluk vardır. Sigmoid çentiğin eğrilik yarıçapı ulnar yuvanınkinden önemli ölçüde daha büyüktür, böylece DRUE aslında kemik uyumu yoluyla stabilite sağlamaz. ${ }^{[7]}$ Stabilite büyük ölçüde yumuşak doku stabilizatörlerine bağlıdır. Sigmoid çentik ile ulnar karşılığı arasındaki eklem yüzeyi teması en fazla \%60'tır ve bu nötral rotasyonda gerçekleşir. Pronasyon ve supinasyonun uç noktalarında, yalnızca \%10 kemik teması vardır. ${ }^{[5]}$ Kemik anatomisi yalnız başına eklem stabilitesinin tahmini \%30'unu sağlar. ${ }^{[12,13]}$ Radiusun distal ucu, proksimal karpal sıranın skafoid ve lunat kemiği ile eklemleşen iki konkav faset içerir. Distal radius karpusu ve el bileğini destekler. Buna karşılık distal ulna, doğrudan karpus ile eklemleşmez.

\section{DISTAL RADYOULNAR EKLEM (DRUE) BIYOMEKANIĞi VE YAPISI}

Distal radyoulnar eklemin mekanik işlevi ön kol rotasyonudur. Pronasyon ve supinasyon olarak da bilinen bu dönme hareketi, ön kolun radius başının merkezinden ulnar başın foveasına uzanan uzunlamasına bir eksen etrafinda oluşan harekettir. DRUE ve proksimal radyoulnar eklem mekanik olarak birbiri ile bağlantılı olduğundan, her iki eklem eş zamanlı olarak çalışmadan etkili bir ön kol rotasyonunun gerçekleşmesi beklenemez. Ön kol rotasyonu, el bilek kompleksine mükemmel bir hareket genişliği sağlar. Karpusa dışsal üçüncü bir hareket derecesini yerleştirmek, elin nesneleri fark edilebilir ve güvenli bir stabilite ile kavraması için sonsuz farklı pozisyonda kullanılabilmesine izin verir. ${ }^{[14]}$ 
Distal radyoulnar eklemde 3 düzlemde hareket meydana gelir: 1) Ön kol ekseninde uzunlamasına rotasyon, 2) Dorsal-palmar translasyon ve 3) Proksimaldistal translasyon. Dönme hareketinin tanımlanması kolaydır, çünkü elin avuç içinin yönüne göre avuç içi yukarı ve avuç içi aşağı doğru $180^{\circ}$ hareket eder. Bununla birlikte, kayda değer bir karmaşıklık vardır. Dönme ekseni, radyal başın merkezinden ulnar başın merkezine çizilen bir çizgidir. Radyal baş, dönme ekseninin proksimal ucu çevresinde (dairesel bağ ile proksimal ulnanın yan tarafına bağlanır) yerinde dönerken, radiusun tüm distal ucu, ulnanın sabit yuvarlak başının etrafinda dönmektedir. Distalde dönme ekseni hareketli distal radiusun dışındadır. Radiusun dönme eksenine göre konumu her zaman pronosupinasyon yayı boyunca değişmektedir. Dorsal-palmar translasyon, kemik uyumu eksikliği, sigmoid çentiğin eğrilik yarıçaplarındaki farklılık ve ulnar baş nedeniyle pronosupinasyonla ortaya çıkar. Pronasyonun son aralığında, ulnar baş sigmoid çentiğin dorsal kenarına yaklaşır, supinasyonun son aralığında, ulnar baş sigmoid çentiğin volar kenarına yaklaşır durumdadır. Distal ulna pronasyon sırasında 2,8 $\mathrm{mm}$ dorsale, supinasyon sırasında ise 5,4 $\mathrm{mm}$ volare translase olur. ${ }^{[12,15]}$ Ulna ön kolun sabit birimidir ve gerçekten hareket eden radius olduğu için terminoloji kafa karıştırıcı olabilir. Bununla birlikte, geleneksel olarak, distal radiusun ve ulnanın göreceli konumu, ulnanın radiusa göre konumu ile adlandırılır. $\mathrm{Bu}$, instabilite modellerini açıklamak için de geçerlidir. DRUE'de proksimal-distal translasyon meydana gelir, çünkü radius sabit ulna üzerinde, tam supinasyondan tam pronasyona geçerken, radiusun ulnaya göre göreceli uzunluğu kısalır ve DRUE'de longitudinal translasyon gerçekleşir.

Distal radyoulnar eklemi değerlendirmek için yaygın olarak kullanılan üç önemli anatomik gösterge vardır:

1- Ulnar varyans distal ulna ile radius arasındaki uzunluk ilişkisini tanımlar. Ulnar varyans, ilk olarak lunat fasetin en proksimal yönünü temsil eden ve ön kolun anatomik uzun eksenine dik olan bir noktayı içeren bir çizgi çizilerek ölçülür. ${ }^{[10]}$ Ulnar kutbun distal kortikal yüzeyini temsil eden ve ayrıca ön kolun anatomik uzun eksenine dik olan bir noktayı içeren başka bir çizgi çizilir. İkinci çizgi birinci çizginin distalinde ise ulnar pozitif varyans mevcuttur. Birinci çizgiye yakın ise ulnar negatif varyans mevcuttur (Şekil 5). ${ }^{[10]}$ Ulnar varyans, radyokarpal eklem boyunca yük dağılımını etkileyecektir. Ulnar pozitif varyansı, TFKK boyunca artan basınç ve yük ile ilişkilidir. Ortalama ulnar varyans 0,9 (4,2 $\mathrm{mm}$ ulna negatif; $2,3 \mathrm{~mm}$ ulna pozitif) $\mathrm{mm}$ ulna negatif olarak tespit edilmiştir. Pronasyon ve supinasyon hareketleri arasında proksimal

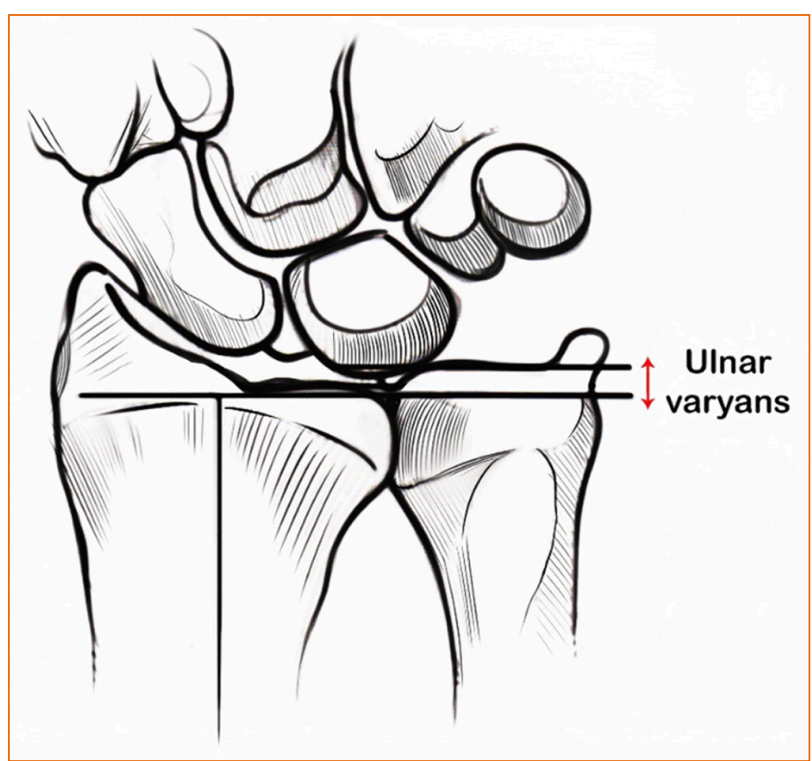

Şekil 5. Ulnar varyans ölçümü.

ve distal translasyon ile yaklaşık 2-4 mm lik ulna yüksekliği değişikliği olabilir. Tam ön kol pronasyonunda ulna yüksekliği daha fazladır. Artmış ulna uzunluğu ulnar impaksiyon ve lunotrikuetral instabilite ile ilişkili iken; azalmış ulna uzunluğu Kienböck hastalığı ile ilişkilidir. ${ }^{116,17]}$

2- Ön düzlemde, DRUE; ön kolun anatomik uzun eksenine $20^{\circ}$ eğik ancak radyoulnar dönme eksenine paralel olarak oturur. Bu ilişki, pronosupinasyon arkı boyunca DRUE üzerinde eşit kurvet aktarımına izin verir. ${ }^{[16,18]}$

3- Sagittal düzlemde, radius son pronasyon aralığında ulnanın daha iyi yerleşmesine izin veren, arkaya doğru bir bükülme sergiler. Ön düzlemde, radiusun kabaca bir manivela şeklinde olan 2 kıvrımı ve 3 farklı bölümü vardır. Bu, ön kolun supinatörlerinin (biseps ve supinator) ve pronatorlarının (pronator kuadratus ve pronator teres) mekanik verimliliğini optimize ederek en üst düzeye çıkarır. ${ }^{[14]}$

\section{DISTAL RADYOULNAR EKLEM LIGAMENTÖZ SINIRLAYICILARI}

Kemik uyumu tarafından sağlanan stabilite sınırlı olduğundan, TFKK'nin bağları DRUE'nin birincil intrinsik stabilizasyonunu sağlar. Ön kolun uzunlamasına rotasyon eksenini geçen IOM, ekstansör retinakulum ve kas tendon üniteleri ilave stabilite sağlar. PRUL ve DRUL, sırasıyla distal radiusun sigmoid çentiğinin palmar ve dorsal kenarlarından başlar ve ulnar tarafa yönelerek ulnar stiloide doğru ilerler. Ulnar stiloide 


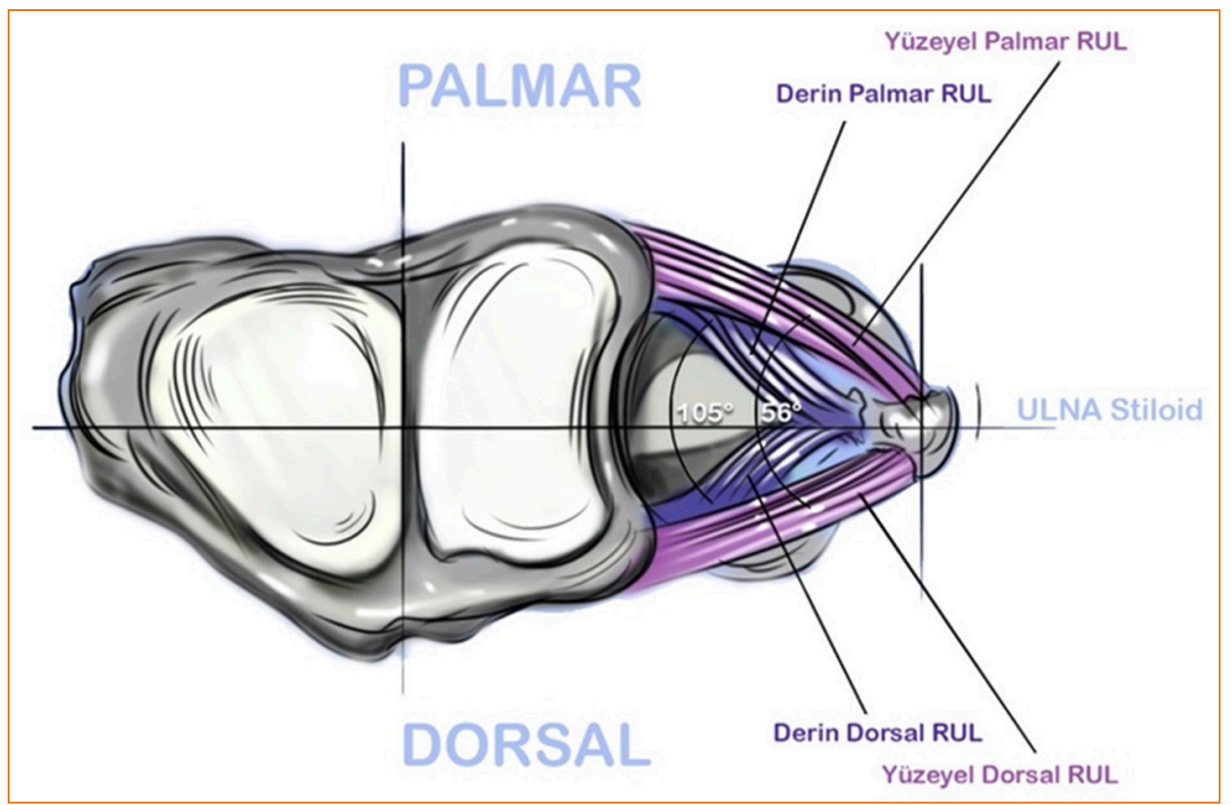

Şekil 6. Palmar radyoulnar ligamentin (PRUL) ve dorsal radyoulnar ligamentin (DRUL) yüzeyel ve derin lifleri.

ulaşmadan önce, her bağın bir dalı ayrılır ve foveaya girer. Her bağın geri kalanı, PRUL ve DRUL'un yüzeyel kısımlarını oluşturarak ulnar stiloide girmeye devam eder (Şekil 6). PRUL ve DRUL'nin derin kısımları ligamentum subkruentum olarak adlandırılır. Yüzeysel PRUL ve DRUL, eklem diskini, TFKK'yi çevreleyen bir üçgen oluşturur. PRUL, DRUL ve TFKK sürekli yayılan bir yapı olsa da, histolojisi ve işlevi farklıdır. PRUL ve DRUL gerçek bağlardır ve normal hareket sırasında DRUE'nin rotasyonunu ve dorsal-palmar translasyonunu sınırlandırarak ve patolojik DRUE ayrılmasını önleyerek eklem hareketini kontrol eder. TFKK, ulnar karpustan ulnaya iletilen sıkıştırıcı yükleri absorbe eder. ${ }^{[10,19]}$

Triangular fibrokartilaj kompleksin palmar tarafinda, iki bağ PRUL'den kaynaklanır ve distalde lunat ve trikuetrum kemiklerine ilerler. Sırasıyla bunlar ulnolunat (UL) ve ulnotrikuetral (UT) bağlar olarak adlandırılırlar. Hem UT hem de UL bağları, karpusun palmar translasyonunu kısıtlar. TFKK'nın kritik yapısal bileşenleridir. ${ }^{[20]}$

Genellikle EKU alt kılıfı olarak adlandırılan EKU tendonunun kılıfı, doğrudan DRUL'a bağlanır, böylece DRUE'ye hem dinamik hem de statik stabilite sağlar. EKU alt kılıfı, üzerinde uzanan ekstansör retinakulumdan farklı olarak 1,5-2,0 cm'lik fibro-osseöz bir tüneldir. ${ }^{[12,21]}$

Palmar radyoulnar ligament (PRUL) ve dorsal radyoulnar ligament (DRUL) iki ayrı sonlanım noktasını paylaşır (foveanın derin kısmı ve ulnar stiloidin yüzeysel kısmı). Derin foveal insersiyon daha geniş ve $105^{\circ}$ tutunma açısına sahipken, yüzeyel ulnar stiloid insersiyonu $56^{\circ}$ tutunma açısına sahiptir. Derin liflerin daha geniş tutunma açısı, pronosupinasyon arkı boyunca ulnanın başı etrafında döndüğü için radiusu kontrol etmede mekanik olarak daha avantajıdır. Pronosupinasyon arkı boyunca derin ve yüzeyel PRUL ve DRUL'de karşılıklı bir sıkışma ve gevşeme olduğu görülür. Supinasyonda, dorsal derin lifler gergin ve dorsal yüzeyel lifler gevşektir. Palmar yüzeyel lifleri gergin ve palmar derin lifleri gevşektir (Şekil 7). Pronasyonda, palmar derin lifleri gergin ve palmar yüzeyel lifleri gevşektir. Dorsal derin lifleri gevşek ve dorsal yüzeyel lifleri gergindir (Şekil 8). Bu karmaşık etkileşim, pronosupinasyon sırasında DRUE'de hem rotasyonu hem de dorsal/palmar translasyonu kontrol eder. ${ }^{[4,22]}$

\section{Triangular Fibrokartilaj Kompleks (TFKK)}

Triangular fibrokartilaj kompleks (TFKK) yapısının tamamı, kısıtlama, kontrol ve yük aktarımının önemli mekanik özelliklerine sahip karmaşık bir üç boyutlu yapı olarak düşünülmeli ve değerlendirilmelidir. Teknik olarak TFKK, uygun üçgen fibrokartilaj (eklem diski), PRUL, DRUL, EKU alt kılıfı, UT bağı, UL bağı ve menisküs homoloğunu içerir (Şekil 9). . ${ }^{[23]}$ Menisküs homoloğu, sigmoid çentiğin distal kenarının dorsal ucuna ve eklem diskinin dorsal sınırına proksimalde bağlanır. Trikuetrum, lunat ve lunotrikuetral bağın ulnar yönüne doğru volare ve distale uzanır. Menisküs homoloğunun ulnar lifleri, EKU alt tabakasının lifleriyle birlikte gelir ve distalde beşinci metakarpın tabanına kadar devam 

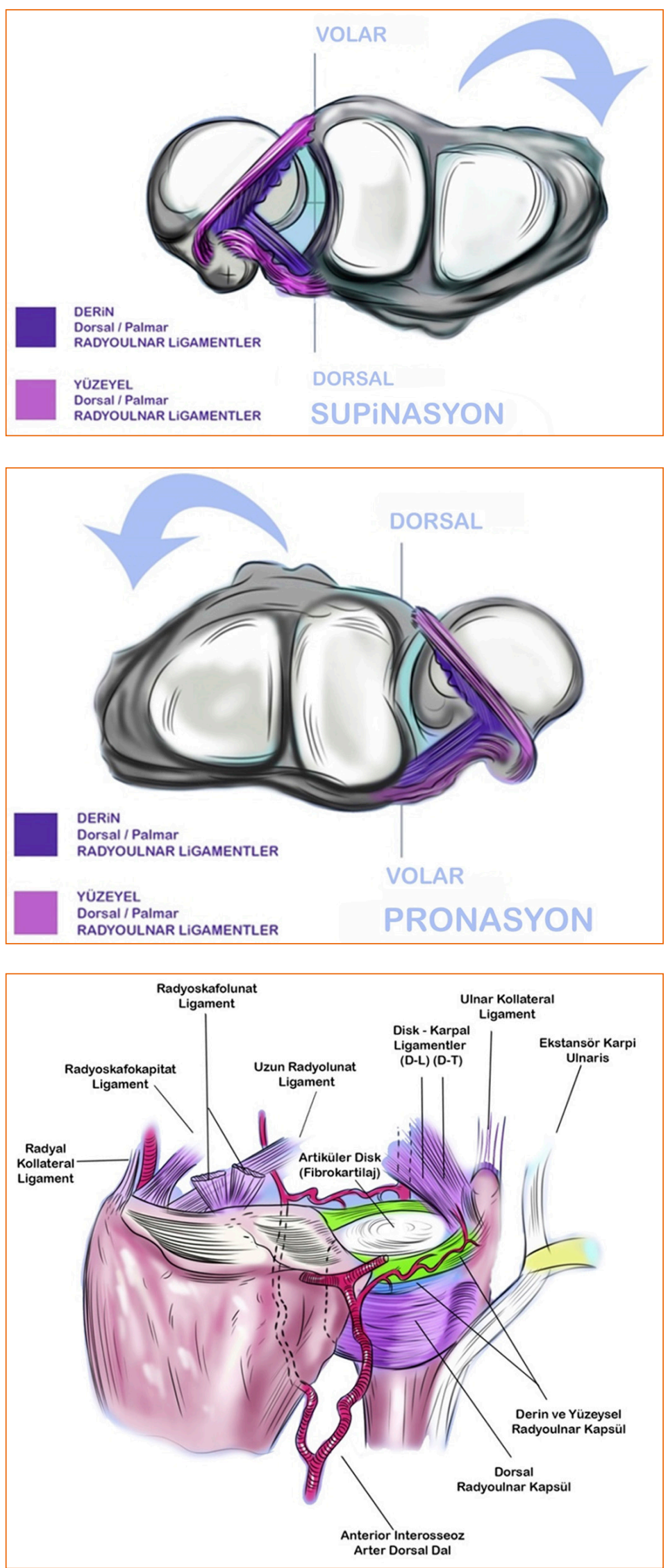

Şekil 7. Supinasyonda palmar radyoulnar ligamentin (PRUL) ve dorsal radyoulnar ligamentin (DRUL) yüzeyel ve derin liflerin durumu.

Şekil 8. Pronasyonda palmar radyoulnar ligamentin (PRUL) ve dorsal radyoulnar ligamentin (DRUL) yüzeyel ve derin liflerin durumu.

Şekil 9. Triangular fibrokartilaj kompleks (TFKK) anatomik yapısı. 


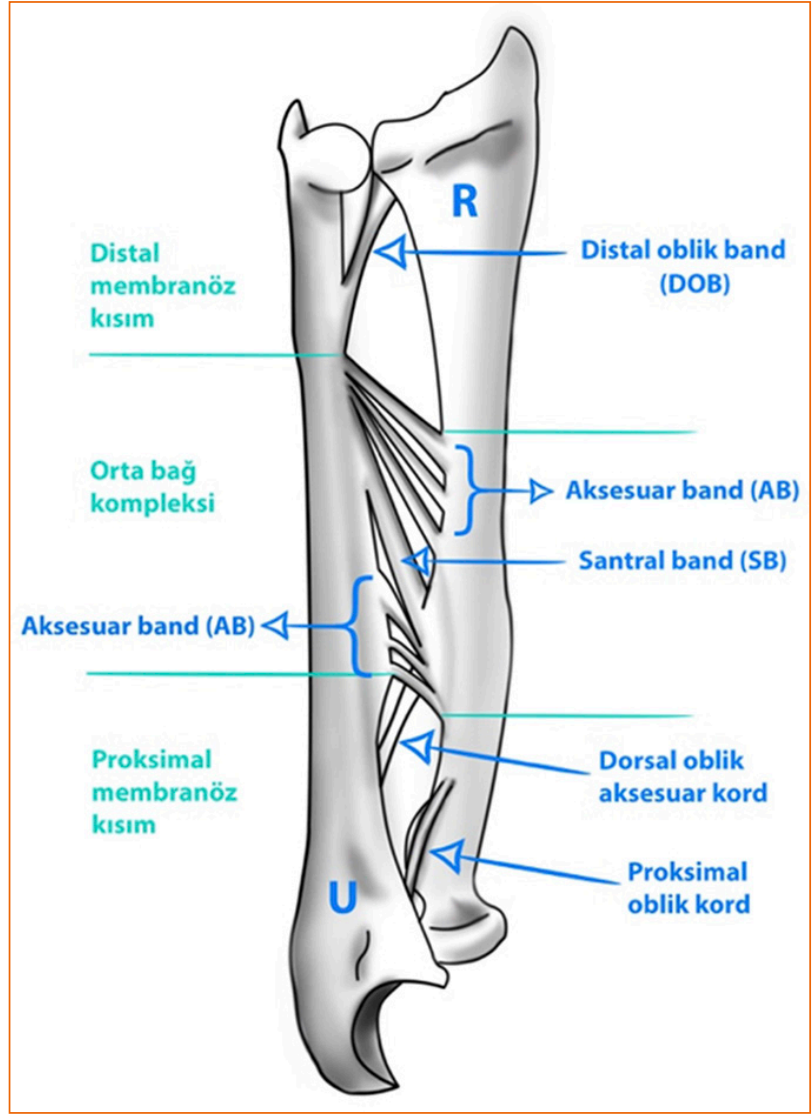

Şekil 10. İnterosseöz membran anatomisi.

eder. ${ }^{[24]}$ Menisküs homologu, iyi damarlanmış gevşek bağ dokusundan oluşur ve paralel bir şekilde yönlenen yoğun kollajen lifleri içermediğinden ve önemli ölçüde uzama kabiliyetine sahip olduğundan gerçek bir bağ değildir. ${ }^{[25]}$ Menisküs homoloğunun işlevi tam olarak anlaşılamamıştır. TFKK bir bütün olarak DRUE'nin birincil stabilizatörü olarak kabul edilir. Karpusun ulnar tarafını ve radiusu ulnanın başından uzaklaştıran (üç boyutlu hamak benzeri bir şekilde) bağ ve kıkırdaklı bir yapıdır ve ulnokarpal yaklaşmada yük aktarımına yardımcı olur. ${ }^{[26-28]}$

\section{İnterosseöz Membran (IOM)}

İnterosseöz membran (IOM), radius ve ulnayı neredeyse tüm uzunlukları boyunca birbirine bağlayan geniş bir bağ yapısıdır. IOM'nin ana işlevi, radius ve ulna arasındaki ilişkiyi pronosupinasyon arkı boyunca stabilize etmektir. IOM farklı bölümlerden oluşur (Şekil 10). Merkez bant, yapının en geniş ve en belirgin kısmıdır ve uzunlamasına bir dengeleyici ve yük iletici olarak işlev görür. ${ }^{[29,30]}$ Merkez bandın lifleri, radiustan ulnaya proksimalden distale doğru uzanır. Bu bağ radius distalde uygulanan yük ile gerilir ve böylece kuvvet ulnaya ve daha sonra proksimale iletilir. iOM'nin merkez bandının lifleri ayrıca bir radius başı yokluğunda radiusun proksimale yer değiştirmesini sınırlar. IOM'nin diğer dört parçası daha vardır: aksesuvar bant, distal oblik demet (DOB), proksimal oblik kord ve dorsal oblik aksesuvar kord. Özellikle ilgi çekici olan, distal ulnar şafttan (pronator kuadratus kasının proksimal kenarında) çıkan ve distale hareket eden ve sigmoid çentiğin alt kenarına giren DOB'dir. $\mathrm{DOB}$, volar ve dorsal instabilitenin kontrolüne katkıda bulunarak DRUE'deki DRUL ve PRUL lifleriyle bütünleşmiş gibi görünmektedir. ${ }^{[31]}$ Pronosupinasyon sırasında DOB'nin uzunluğunda çok az değişiklik olduğu için, ön kolun izometrik bir stabilizatörü olduğu düşünülmektedir. ${ }^{[32]}$

\section{Dinamik Stabilizatörler}

Ekstansör karpiulnaris (EKU) ve pronator kuadratus, DRUE'nin dinamik stabilitesine katkıda bulunur. EKU'nun hareketi, ulnar karpusu dorsale kaldırır ve pronasyon sırasında ulna başını palmar yöne doğru bastırarak, ulnada distal radiusun dolaylı olarak palmar translasyonunu kısıtlar. ${ }^{[12,21]}$ Pronator kuadratusun iki başı vardır: Yüzeysel ve derin. Yüzeysel baş ulnadan çıkar, enine seyreder, radiusa yapışır ve birincil ön kol pronatoru olarak işlev görür. Derin baş, ulnada daha proksimalde ortaya çıkar, oblik seyreder ve radius üzerinde daha distale yapışır. Aktif pronasyon ve pasif supinasyon sırasında distal ulnayı sigmoid çentiğe çekerek dinamik DRUE stabilitesine katkıda bulunur. ${ }^{[33,34]}$ iOM'nin DOB'nin ve palmar ve dorsal RUL'lerin statik kısıtlamalarını dinamize eder. Hagert, pronator kuadratusun DRUE gevşekliğinde nöromusküler eğitim programlarında önemli olabileceğini öne sürüyor.

\section{DISTAL RADYOULNAR EKLEMDE DINAMIK KUVVETLER}

Dört kas DRUE'de hareketi yönlendirir: İki pronator ve iki supinator. Pronator kuadratus ve pronator teres olmak üzere median sinir ile innerve olan iki adet pronator vardır. Biri intrinsiktir (ön koldaki pronator kuadratus) ve birisi ekstrinsiktir (pronator teres ön kolun dışına uzanır). ìki supinatör vardır: Biseps braki ve supinator. Biseps braki, muskülokütan sinir tarafindan innerve edilen ekstrinsik bir kas iken; supinator kas radyal sinir tarafindan innerve edilir ve intrinsik bir kastır. ${ }^{[9]}$

\section{Gerilim ve Bütünlük}

Hagert, DRUE stabilitesini açıklamak için yapısal gerginlik kavramını kullanır. Tensegrity, gerilim ve 

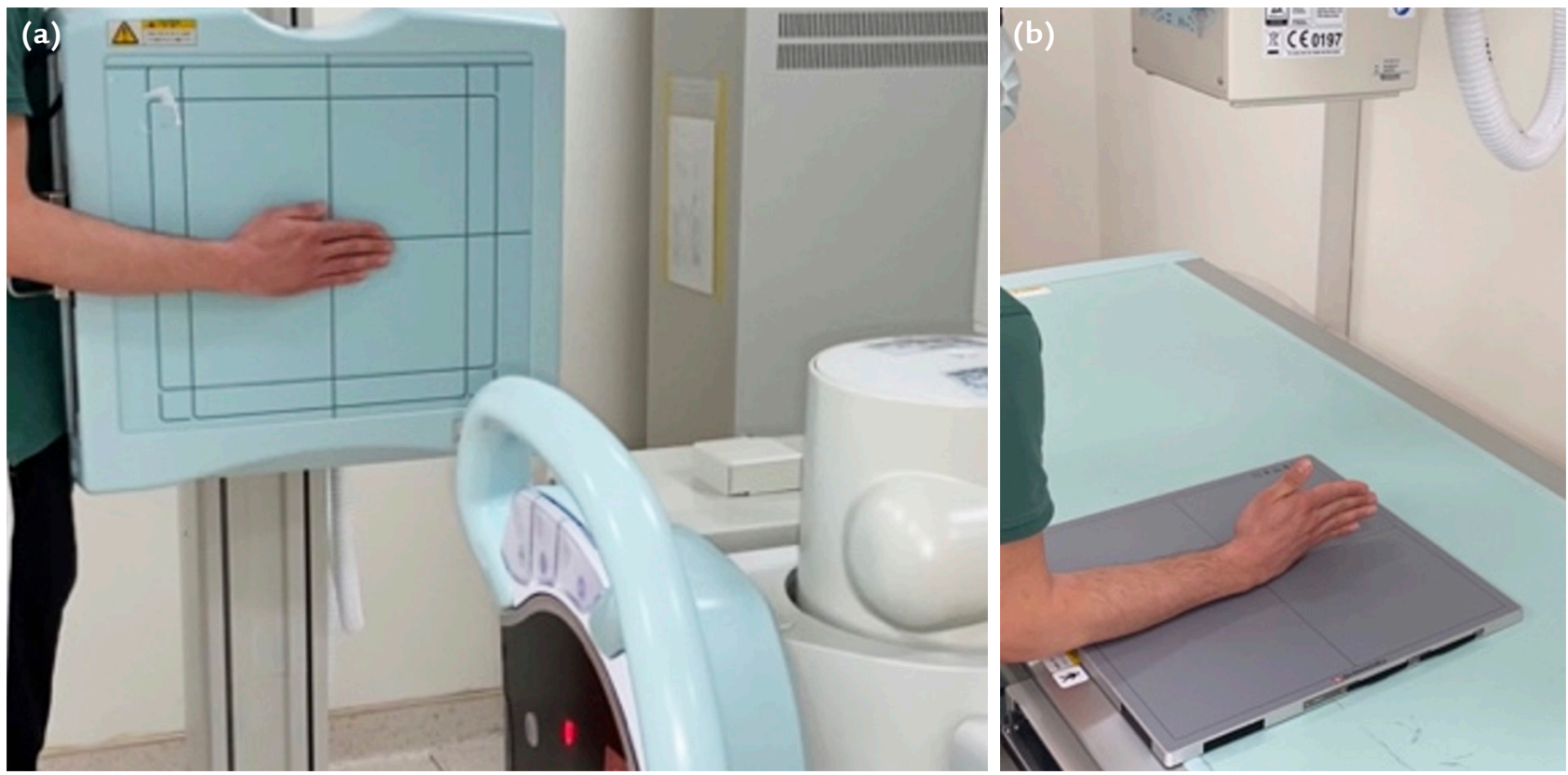

Şekil 11. a, b. Distal radyoulnar eklem (DRUE) arka-ön (PA) görüntüleme (a). Distal radyoulnar eklem (DRUE) yan görüntüleme (b).

sıkıştırma kuvvetlerinin sinerjisi, bütünlüğü olarak tanımlanır. ${ }^{[35]}$ Gerilim ve sıkıştırma, yapısal sistemlerin ayrılmaz ve koordinat işlevleridir, tek tek elemanların mukavemeti nedeniyle değil, tüm yapının mekanik gerilimleri dağıtma ve dengeleme biçimi nedeniyle mekanik olarak kararlıdır. DRUE stabilitesi, eklemi geçen kasların getirdiği dinamik kuvvetlerden daha fazla etkilenen kemikler ve bağlar boyunca gerilme ve sıkıştırma kuvvetlerinin karmaşık bir etkileşiminden kaynaklanır. ${ }^{[36]}$

\section{STABILIZASYONDA ETKISI OLMAYAN YAPILAR}

$\mathrm{Bu}$ yapılar arasında; ulnokarpal kapsül, menisküs homoloğu ve ligamentum subkruentum yer alır.

\section{Ulnokarpal Kapsül}

Ulnokarpal kapsül, ulnar kollateral bağ olarak da adlandırılır. Ancak biyomekanik özellikleri gerçek bir ligamentöz yapı olarak sınıflandırılamamasına sebep olur. ${ }^{[24]}$ Ulnotrikuetral bağın ulnar kenarından başlar, dorsalde EKU tendonuna uzanır. Ulnar stiloid etrafinı sarar ve distalde trikuetruma yapışır. Bu yapı ulna kırıklarında veya eklem yaralanmalarının ardından fibrotik hale gelir ve rotasyonu sınırlar. ${ }^{[37]}$

\section{Menisküs Homoloğu}

Menisküs homoloğu ulna kapsülü ile DRUE'nin yüzeyel kısmı arasında uzanan bir dokudur. Bu bölge; artroskopik olarak görülen prestiloid çıkmazı içerir. ${ }^{[24]}$ Bu dokunun fonksiyonu tam anlamıyla henüz bilinmemesine rağmen muhtemelen sinovyumdan kaynaklanan ve iyi kanlanan bir yapı olduğu bilinmektedir.

\section{Ligamentum Subkruentum}

Ulna stiloidin yanında zengin kanlanan, DRUE'nin iki kısmı arasında yer alan boşlukta bulunan dokunun adı ligamentum subkruentumdur. Bu doku bir bağ olarak adlandırılmasına rağmen DRUE'ye belirgin bir stabilite sağladığı görülmez. Histolojik çalışmalar gerçek ligamentöz doku içermediğini göstermiştir.

\section{EKLEM INNERVASYONU}

Anatomik çalışmalarda DRUE'nin innervasyonunun üç farklı alandan olduğu gösterilmiştiri ${ }^{[38,39]}: 1$ ) Dorsal bölge; dorsal radyoulnar ve ulnokarpal eklem kapsülünü, dorsal radyoulnar bağı içerir ve posterior interosseöz sinirin terminal dalı ile innerve olur. 2) Ulnar bölge; menisküs homoloğu, ulnotrikuetral bağ ve foveal yapışma yerini içerir, ulnar sinirin dorsal duyusal dalı ile innerve olur. 3) Volar bölge volar radyoulnar eklem kapsülü, volar radyoulnar ve ulnolunat bağlar ulnar sinir proper dalı ile innerve olur.

Anterior interosseöz sinir volar DRUE kapsülünün yakınından geçse de DRUE bağlarına girdiği gösterilememiştir. Benzer biçimde medial antebrakiyal kutanöz sinir de DRUE'de eklem dışı seyir gösterir. ${ }^{[40]}$ 


\section{UYGUN EL BILEĞi RADYOGRAFI POZISYONU}

Distal radyoulnar eklemin doğru arka-ön radyografi ve doğru yan radyografi tetkiki için şu adımlar takip edilmelidir;

1) Kol gövdeye tam addükte edilir.

2) Ön kol nötral poziyonda iken dirsek $90^{\circ}$ fleksiyona getirilir.

3) El ve parmaklar nötral pozisyonda iken başparmak ikinci metakarp kenarında birleştirilir (Şekil 11). ${ }^{[35,41]}$

\section{SONUÇ}

Distal radyoulnar eklem, distal radius ve ulnanın mükemmel kemik uyumu ve distal radyoulnar ile ulnokarpal bağların bütünlüğü sayesinde ön kol rotasyonuna izin veren; biyomekanik özellikleri ile elin ileri düzeydeki becerisine önemli katkılar sağlayan karmaşık bir eklemdir.

\section{Teşekkür}

Şekillerin çizimine olan katkılarından dolayı Erciyes Ünv. Güzel Sanatlar Fak. Görsel Illetişim Tasarımı Bölümü'nden Öğr. Gör. Dr. Onur Toprak'a teşekkür ederiz.

\section{KAYNAKLAR}

1. Kakar S. Garcia-Elias M. The "four-leaf clover" treatment algorithm: a practical approach to manage disorders of the distal radioulnar joint. J Hand Surg Am 2016;41(4):551-64. Crossref

2. Tolat AR, StanleyJK, Trail IA. A cadaveric study of the anatomy and stability of the distal radioulnar joint in the coronal and transverse planes. J Hand Surg Br 1996;21(5):587-94. Crossref

3. Tolat AR, Sanderson PL, De Smet L, Stanley JK. The gymnast's wrist: acquired positive ulnar variance following chronic epiphyseal injury. J Hand Surg $\mathrm{Br}$ 1992;17(6):678-81. Crossref

4. Ekenstam FAF, Hagert CG. Anatomical studies on the geometry and stability of the distal radio ulnar joint. Scand J Plast Reconstr Surg 1985;19(1):17-25. Crossref

5. Kihara $\mathrm{H}$, Short $\mathrm{WH}$, Werner FW, Fortino MD, Palmer AK. The stabilizing mechanism of the distal radioulnar joint during pronation and supination. J Hand Surg Am 1995;20(6):9306. Crossref

6. Ward LD, Ambrose CG, Masson MV, Levaro F. The role of the distal radioulnar ligaments, interosseous membrane, and joint capsule in distal radioulnar joint stability. J Hand Surg Am 2000;25(2):341-51. Crossref

7. Kleinman WB. Stability of the radioulnar joint. Biomechanics, pathophysiology, physical diagnosis and restoration of functionwhat we have learned in 25 years. J Hand Surg Am 2007;32(7):1086-106. Crossref

8. Thomas BP, Sreekanth R. Distal radioulnar joint injuries. Indian J Orthop 2012;46(5):493-504. Crossref
9. Hagert CG. The distal radioulnar joint in relation to the whole forearm. Clin Orthop Relat Res 1992;(275):56-64. Crossref

10. Katolik LI, Trumble T. Distal radioulnar joint dysfunction. J Hand Surg Am 2005;5(1):8-29. Crossref

11. Thiru-Pathi RG, Ferlic DC, Clayton ML, McClure DC. Arterial anatomy of the triangular fibrocartilage of the wrist and its clinical significance. J Hand Surg Am 1986;11(2):258-63. Crossref

12. Huang JI, Hanel DP. Anatomy and biomechanics of the distal radioulnar joint. Hand Clin 2012;28(2):157-63. Crossref

13. Stuart PR, Berger RA, Linscheid RL, An KN. The dorsopalmar stability of the distal radioulnar joint. J Hand Surg Am 2000;25(4):689-99. Crossref

14. Kapandji IA. The Physiology of the Joints, Vol 1: Upper Limb, 5th ed. New York, NY: Churchill Livingstone; 1982. p.98-128. http://graphics.cs.cmu.edu/nsp/course/16899-s16/papers/ Kapandji.pdf

15. Pirela-Cruz MA, Goll SR, Klug M, Windler D. Stress computed tomography analysis of the distal radioulnar joint: a diagnostic tool for determining translational motion. J Hand Surg Am 1991;16(1):75-82. Crossref

16. Linscheid RL. Biomechanics of the distal radioulnar joint. Clin Orthop Relat Res 1992;(275):46-55. Crossref

17. Palmer AK, Glisson RR, Wemer FW. Relationship between ulnar variance and triangular fibrocartilage complex thickness. J Hand Surg Am 1984;9(5):681-3. Crossref

18. Ekenstam FAF. Anatomy of the distal radioulnar joint. Clin Orthop Relat Res 1992;(275):14-8. Crossref

19. Palmer AK, Werner FW. Biomechanics of the distal radioulnar joint. Clin Orthop Relat Res 1984;(187):26-35. Crossref

20. Sasao S, Beppu M, Kihara H, Hirata K, Takagi M. An anatomical study of the ligaments of the ulnar compartment of the wrist. Hand Surg 2003;8(2):219-26. Crossref

21. Spinner M, Kaplan EB. Extensor carpi ulnaris. Its relationship to the stability of the distal radio-ulnar joint. Clin Orthop Relat Res 1970;68:124-9. Crossref

22. Schuind F, An KN, Berglund L, Rey R, Cooney WP, Linscheid $\mathrm{RL}$, Chao EY. The distal radioulnar ligaments: a biomechanical study. J Hand Surg Am 1991;16(6):1106-14. Crossref

23. Nakamura T, Yabe Y, Horiuchi Y. Functional anatomy of the triangular fibro-cartilage complex. J Hand Surg $\mathrm{Br}$ 1996;21(5):581-6. Crossref

24. Ishii S, Palmer AK, Werner FW, Short WH, Fortino MD. An anatomic study of the ligamentous structure of the triangular fibrocartilage complex. J Hand Surg Am 1998;23(6):977-85. Crossref

25. Garcia-Elias M. Soft-tissue anatomy and relationships about the distal ulna. Hand Clin 1998;14(2):165-76. Crossref

26. Palmer AK, Werner FW. The triangular fibrocartilage complex of the wrist: anatomy and function. J Hand Surg Am 1981;6(2):153-62. Crossref

27. Nakamura T, Takayama S, Horiuchi Y, Yabe Y. Origins and insertions of the triangular fibrocartilage complex: a histological study. J Hand Surg Br 2001;26(5):446-54. Crossref

28. Nakamura T, Makita A. The proximal ligamentous component of the triangular fibrocartilage complex. Functional anatomy and three-dimensional changes in length of the radioulnar ligament during pronation and supination. J Hand Surg $\mathrm{Br}$ 2000;25(5):479-86. Crossref

29. Noda K, Goto A, Murase T, Sugamoto K, Yoshikawa H, Moritomo $\mathrm{H}$. Interosseous membrane of the forearm: an anatomical study of ligament attachment locations. J Hand Surg Am 2009;34(3):415-22. Crossref 
30. Watanabe $H$, Berger RA, Berglund LJ, Zobitz ME, An KN. Contribution of the interosseous membrane to distal radioulnar joint constraint. J Hand Surg Am 2005;30(6):1164-71. Crossref

31. Kitamura $T$, Morimoto $H$, Arimitsu S, Berglund LJ, Zhao KD, An KN, Rizzo M. The biomechanical effect of the distal interosseous membrane on distal radioulnar joint stability: a preliminary anatomic study. J Hand Surg Am 2011;36(10):1626-30. Crossref

32. Moritomo $\mathrm{H}$. The distal interosseous membrane: current concepts in wrist anatomy and biomechanics. J Hand Surg Am 2012;37(7):1501-7. Crossref

33. Stuart PR. Pronator quadratus revisited. J Hand Surg $\mathrm{Br}$ 1996;21(6):714-22. Crossref

34. Johnson RK, Shrewsbury MM. The pronator quadratus in motions and in stabilization of the radius and ulna at the distal radioulnar joint. J Hand Surg Am 1976;1(3):205-9. Crossref

35. Hagert E, Hagert CG. Understanding stability of the distal radioulnar joint through an understanding of its anatomy. Hand Clin 2010;26(4):459-66. Crossref

36. Altman E. The ulnar side of the wrist: clinically relevant anatomy and biomechanics. Journal of Hand Therapy 2016;29(2):111-22.Crossref
37. Kleinman WB, Graham TJ. The distal radioulnar joint capsule: clinical anatomy and role in posttraumatic limitation of forearm rotation. J Hand Surg Am 1998;23(4):588-99. Crossref

38. Gupta R, Nelson SD, Baker J, Jones NF, Meals RA. The innervation of the triangular fibrocartilage complex: Nitric acid maceration rediscovered. Plast Reconstr Surg 2001;107(1):135-9. Crossref

39. Shigemitsu T, Tobe M, Mizutani K, Murakami K, Ishikawa Y, Sato F. Innervation of the triangular fibrocartilage complex of the human wrist: quantitative immunohistochemical study. Anat Sci Int 2007;82(3):127-32. Crossref

40. Fukumoto K, Kojima T, Kinoshita $Y$, Koda M. An anatomic study of the innervation of the wrist joint and Wilhelm's technique for denervation. J Hand Surg Am 1993;18(3):4849. Crossref

41. Gilula LA, Mann FA, Dobyns JH, Yin Y. Wrist terminology as defined by the International Wrist Investigators' Workshop (IWIW). J Bone Joint Surg Am 2002;84(Suppl 1):1-66. Crossref 